\title{
Multicomponent ion transport in a mono- and bilayer cation- exchange membrane at high current density
}

\author{
S. Moshtarikhah ${ }^{1}$ - N. A. W. Oppers ${ }^{1} \cdot$ M. T. de $\operatorname{Groot}^{2} \cdot$ J. T. F. Keurentjes ${ }^{1}$. \\ J. C. Schouten ${ }^{1} \cdot$ J. van der Schaaf ${ }^{1}$
}

Received: 13 June 2016/Accepted: 18 October 2016/Published online: 14 November 2016

(c) The Author(s) 2016. This article is published with open access at Springerlink.com

\begin{abstract}
This work describes a model for bilayer cationexchange membranes used in the chlor-alkali process. The ion transport inside the membrane is modeled with the Nernst-Planck equation. A logistic function is used at the boundary between the two layers of the bilayer membrane to describe the change in the properties of each membrane layer. The local convective velocity is calculated inside the membrane using the Schlögl equation and the equation of continuity. The model calculates the ion concentration profiles inside the membrane layers. Modeling results of mono- and bilayer membranes are compared. The changes in membrane voltage drop and sodium selectivity are predicted. The concentration profile of sodium ions in the bilayer membrane is significantly different from the
\end{abstract}

monolayer membrane. Without the applied current, a linear change in the sodium concentration is observed in the monolayer membrane and in each layer of the bilayer membrane. With an increase in current density, the stronger electromotive force in the carboxylate layer causes a decrease in the sodium concentration in the sulfonate layer, down to the fixed ionic group concentration. This significant decrease of sodium ion concentration in the sulfonate layer results in low concentrations of counter ions and as a consequence a higher permselectivity of the bilayer membrane is obtained when compared to the single-layer membrane. As a drawback, the resistance in the bilayer membrane increases.
J. van der Schaaf

j.vanderschaaf@tue.nl

1 Eindhoven University of Technology, P.O. Box 513, 5600 MB Eindhoven, The Netherlands

2 Akzo Nobel Industrial Chemicals B.V., P.O. Box 247, 3800 AE Amersfoort, The Netherlands 


\section{Graphical Abstract}

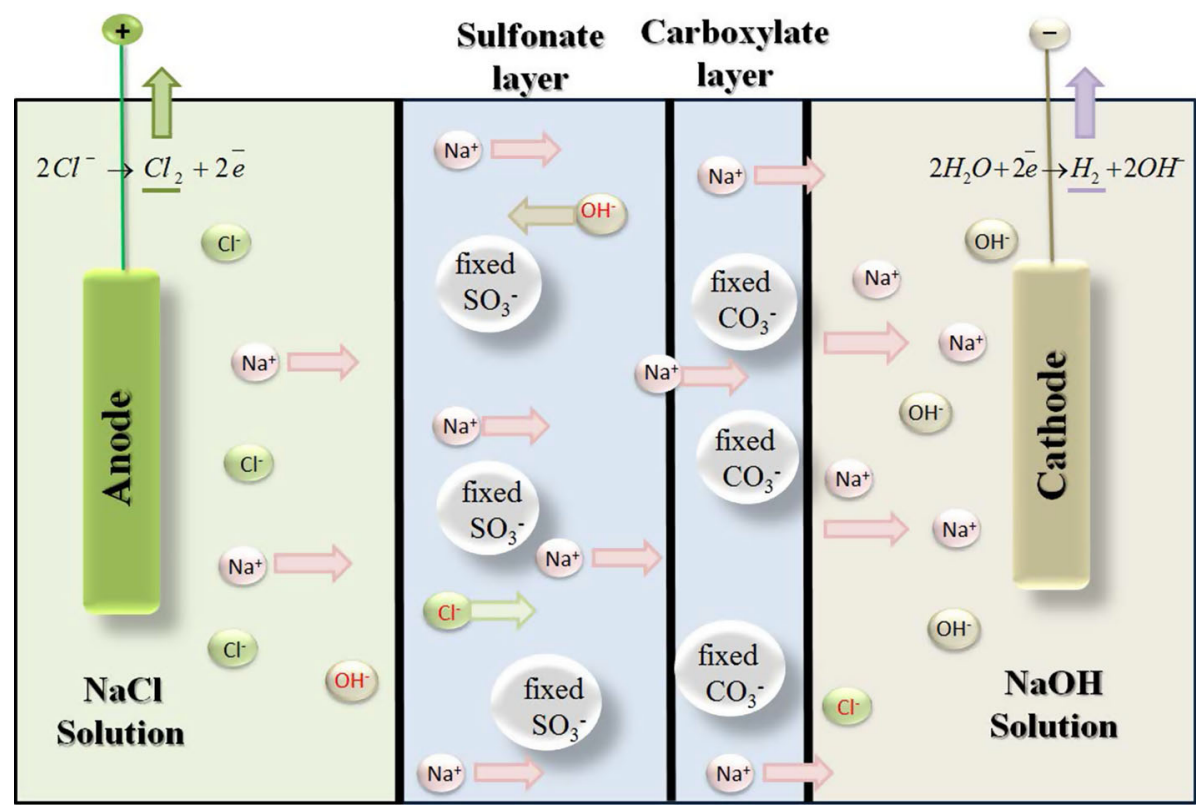

Keywords Multicomponent ion transport - NernstPlanck $\cdot$ Concentration profiles $\cdot$ Bilayer membrane $\cdot$ High current density

\section{List of symbols}

\section{Latin symbols}

A Membrane cross sectional area $\left[\mathrm{m}^{2}\right]$

C Concentration $\left(\mathrm{mol} \mathrm{m}^{-3}\right)$

$d_{\mathrm{h}} \quad$ Hydrodynamic permeability $\left(\mathrm{kg} \mathrm{s} \mathrm{m}^{-3}\right)$

$D \quad$ Diffusion coefficient $\left(\mathrm{m}^{2} \mathrm{~s}^{-1}\right)$

$f \quad$ Fraction in cluster (-)

$F \quad$ Faraday constant $\left(\mathrm{C} \mathrm{mol}^{-1}\right)$

I Current density $\left(\mathrm{A} \mathrm{m}^{-2}\right)$

$J \quad$ Flux $\left(\mathrm{mol} \mathrm{m}^{-2} \mathrm{~s}^{-1}\right)$

$P \quad$ Pressure $(\mathrm{Pa})$

$R \quad$ Gas constant $\left(\mathrm{J} \mathrm{mol}^{-1} \mathrm{~K}^{-1}\right)$

$t \quad$ Time (s)

$t_{\mathrm{i}} \quad$ Ion transport number (-)

$T$ Temperature (K)

$T_{\mathrm{c}} \quad$ Temperature $\left({ }^{\circ} \mathrm{C}\right)$

$V \quad$ Volume $\left(\mathrm{m}^{3}\right)$

$\bar{V} \quad$ Partial molar volume $\left(\mathrm{m}^{3} \mathrm{~mol}^{-1}\right)$

$W \quad$ Weight fraction (\%)

$W_{\mathrm{e}} \quad$ Weight fraction of adsorbed electrolyte (\%)

$W_{\mathrm{e}}^{\mathrm{s}} \quad$ Weight fraction of adsorbed electrolyte in sulfonate layer $(\%)$

$W_{\mathrm{e}}^{\mathrm{c}} \quad$ Weight fraction of adsorbed electrolyte in carboxylate layer (\%)

$x^{\prime} \quad$ Dimensionless length (-)

$z \quad$ Valence (-)

\section{Greek symbols}

$\delta \quad$ Membrane thickness (m)

$\varphi \quad$ Electrical potential (V)

$\Delta \quad$ Difference (-)

$\nabla \quad$ Gradient $(-)$

$\rho \quad$ Density $\left(\mathrm{g} \mathrm{cm}^{-3}\right)$

$v$ Convective volume flux $\left(\mathrm{m}^{3} \mathrm{~m}^{-2} \mathrm{~s}^{-1}\right)$

$\varepsilon \quad$ Porosity (-)

$\begin{array}{ll}\text { Superscript and subscript } \\ \text { A } & \text { Anolyte } \\ \text { Am } & \text { Anolyte/membrane } \\ \text { c } & \text { Carboxylate } \\ \text { diff } & \text { Diffusion layer } \\ \text { e } & \text { Electrolyte } \\ \text { i } & \text { Species } \\ \text { int } & \text { Interface } \\ \text { m } & \text { Membrane fixed group } \\ \mathrm{m}, 0 & \text { Membrane interface } \\ \mathrm{s} & \text { Sulfonate }\end{array}$

\section{Introduction}

Bilayer cation-exchange membranes are used in the chloralkali process in which sodium chloride and sodium hydroxide are used as the anolyte and catholyte solutions, respectively. Perfluorinated membranes have been modified to increase the permselectivity of the membrane and the overall current efficiency of the process. The replacement of monolayer by bilayer membranes in the chloralkali process increased the current efficiency from 85 to 
$97 \%$ [1]. Bilayer cation-exchange membranes are made by modifying the catholyte side of the membrane or adding an extra layer to that side. In the chlor-alkali technology, the extra layer on the cathode side is either a sulfonate layer with a different equivalent weight or a carboxylate layer. The carboxylate layer typically has a lower conductivity compared to the sulfonate layer, and it has a lower water content. The bilayer membrane is made either by laminating or co-extrusion [1].

In spite of a number of literature studies on the structure of cation-exchange membranes [2-7], there have been few studies looking into the structure and performance of bilayer membranes individually [8-10]. Also, virtually, no data exist in the literature that compares the performance of mono- and bilayer cation-selective membranes especially at high current densities. There are various methods to model ion transport in ion-exchange membranes, and these have been reviewed and modeled by several authors [11-13]. In our earlier paper [14], we developed a NernstPlanck model of multicomponent ion transport through a cation-exchange membrane for a monolayer membrane. The model was validated with experiments using same electrolyte solutions with identical anolyte and catholyte concentrations. In this paper, the ion transport in the monoand bilayer membranes is compared using the NernstPlanck equation. The bilayer membrane is assumed to be with the sulfonic/carboxylic polymers.

The concentration profiles of the charged species and water in the boundary layer and inside the mono- and bilayer membranes are calculated by solving the NernstPlanck equation. The concentration profiles of the ions and water are compared. The potential drop over the membrane and the membrane permselectivity is determined for current densities up to $20 \mathrm{kA} \mathrm{m}^{-2}$.

\subsection{Model approach and assumptions}

To model the ion transport inside the membrane, a one dimensional Nernst-Planck equation is used for both monoand bilayer membranes. The molar flux density in each layer of the membrane is defined with Eq. (1). The current density is an important parameter when investigating high current density operation. It is directly related to the flux of charged species as presented in Eq. (2). The convective velocity is described using the Schlögl equation (Eq. 3). The electroneutrality and mass continuity should hold which are presented by Eqs. (4) and (5). The local electrolyte composition inside the membrane changes, which results in a change of density locally in the membrane. The mixture density (Eq. 6) is used to calculate the local density of the electrolyte in the membrane [1]. The local electrolyte concentration in the membrane is calculated based on the estimation method used by Bouzek et al. [15]. The local voltage drop is calculated from Eq. (7), which is derived from Eq. (2). Equation (8) describes the material balance to solve the system of Eqs. (1) to (7).

$$
\begin{aligned}
& J_{i}=-D_{i} \nabla C_{i}-z_{i} D_{i} C_{i} \frac{F}{R T} \nabla \varphi+C_{i} v \\
& I=F \sum_{i=1}^{n} z_{i} J_{i} \\
& v=d_{\mathrm{h}}\left(z_{\mathrm{m}} C_{\mathrm{m}} F \nabla \varphi-\nabla P\right) \\
& \sum C_{i} z_{i}=0 \\
& -\nabla(\rho v)=0 \\
& \rho \times 10^{-3}=1.006+0.001 W_{\mathrm{NaOH}}-0.17 \times 10^{-4} W_{\mathrm{NaOH}}^{2} \\
& -0.35 \times 10^{-3} T_{\mathrm{c}}-0.21 \times 10^{-5} T_{\mathrm{c}}^{2} \\
& +0.007 W_{\mathrm{NaCl}} \\
& \nabla \varphi=\frac{\frac{I}{F}+\sum_{i=1}^{n} z_{i} D_{i} \nabla C_{i}-v \sum_{i=1}^{n} z_{i} C_{i}}{-\frac{F}{R T} \sum_{i=1}^{n} z_{i}^{2} D_{i} C_{i}} \\
& \frac{\mathrm{d} C_{i}}{\mathrm{~d} t}=-\nabla\left(J_{i}\right)
\end{aligned}
$$

A logistic function is implemented for describing the change in properties of the membrane from the anolyte side layer to the catholyte side layer. The logistic function was chosen to have a gradual change and avoid numerical instabilities and to avoid a discontinuity when solving the partial differential equations with MATLAB. The general logistic function is shown in Eq. (9) in which $A$ and $B$ are the lower and upper asymptote values respectively, $k$ defines the slope of the curve, and $x_{0}$ is the midpoint of the curve.

$f(x)=A+\frac{B-A}{1+\mathrm{e}^{-k\left(x-x_{0}\right)}}$

The fixed ionic group concentration is the property that changes most significantly between the two layers of the membrane. The concentration of fixed ionic groups is defined with Eq. (10). In this equation, the electrolyte uptake and the equivalent weight of each layer in the membrane are different. The electrolyte uptake is assumed to be equal to the water uptake of each layer and is calculated based on Eqs. (11) and (12) for the sulfonated and carboxylated layers, respectively [1].

$$
\begin{aligned}
C_{\mathrm{m}}= & \frac{1000 \times \rho_{\mathrm{e}}}{E W \times W_{\mathrm{e}}}\left(\frac{f_{\mathrm{m}}}{f_{\mathrm{e}}}\right) \\
W_{\mathrm{e}}^{\mathrm{s}}= & -0.0052 \times\left(0.001 C_{\mathrm{e}}\right)^{3}+0.1655 \times\left(0.001 C_{\mathrm{e}}\right)^{2} \\
& -2.7085 \times\left(0.001 C_{\mathrm{e}}\right)+36.682 \\
W_{e}^{c}= & -0.0033 \times\left(0.001 C_{e}\right)^{3}+0.1157 \times\left(0.001 C_{e}\right)^{2} \\
& -1.7809 \times\left(0.001 C_{e}\right)+18.618
\end{aligned}
$$


The fixed ionic group concentration is defined with the logistic function as presented in Eq. (13) in which $x_{0}$ is zero and the slope of the curve is chosen 120. The slope of the curve defined the thickness of the transition state in the logistic function. It is $11 \%$ of the total grid length which is calculated based on 5 and $95 \%$ of the lower and upper asymptote values, respectively. The schematic of the logistic function for the fixed ionic group concentration inside the membrane is shown in Fig. 1.

$C_{\mathrm{m}}(x)=C_{\mathrm{m}}^{\mathrm{s}}+\frac{\left(C_{\mathrm{m}}^{\mathrm{c}}-C_{\mathrm{m}}^{\mathrm{s}}\right)}{\left(1+e^{-k\left(x-x_{0}\right)}\right)}$

The boundary conditions at the membrane-solution interface are summarized in Eqs. (14) and (15) [14]:

$$
\begin{aligned}
& \frac{D_{i}^{\mathrm{e}}}{\delta_{\mathrm{diff}}}\left(C_{i}^{A, e}-C_{i}^{A, \text { int }}\right)+v C_{i}^{A, \text { int }} \varepsilon \\
& =\left(-D_{i} \frac{d C_{i}^{A m, \text { int }}}{d x^{\prime}}-z_{i} D_{i} C_{i}^{A m, \text { int }} \frac{F}{R T} \frac{d \varphi}{d x^{\prime}}+v C_{i}^{A m, \text { int }} \delta\right) \frac{1}{\delta} \varepsilon
\end{aligned}
$$

$$
\begin{aligned}
& C_{i, p o s}^{A m, \text { int }}=C_{i, p o s}^{m, 0} \sqrt{\frac{\sum_{i}^{N_{\text {ions }}} C_{i, \text { neg }}^{m, 0}}{\sum_{i}^{N_{\text {ions }}} C_{i, p o s}^{m, 0}} ;} \\
& C_{i, \text { neg }}^{A m, \text { int }}=C_{i, \text { neg }}^{m, 0} \sqrt{\frac{\sum_{i}^{N_{\text {ions }}} C_{i, p o s}^{m, 0}}{\sum_{i}^{N_{\text {ions }}} C_{i, \text { neg }}^{m, 0}}}
\end{aligned}
$$

Constant pressure and temperature are assumed. Electrolyte solutions are assumed to be ideal. The electrolytes are sodium chloride as anolyte and sodium hydroxide as catholyte. A very high mass transfer at the membrane is assumed to avoid steep concentration gradients in the boundary layers. The spinning disc technology which works based on high-shear forces induced with high-

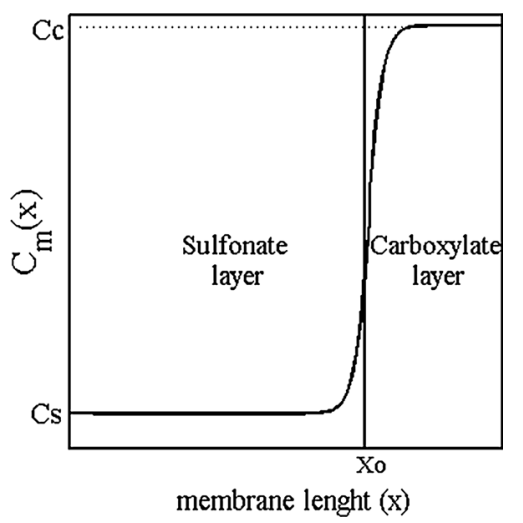

Fig. 1 Schematic of the logistic function expressing the fixed ionic group concentration in the bilayer membrane. $\mathrm{C}_{\mathrm{m}}^{\mathrm{s}}$ and $\mathrm{C}_{\mathrm{m}}^{\mathrm{s}}$ are the fixed ionic group concentrations in the sulfonate and the carboxylate layers, respectively. $\mathrm{X}_{0}$ is the midpoint of the curve which is the transition point between the sulfonate and the carboxylate layers velocity gradient or high-gravity situations has proven [16-19] to have high mass transfer rate from the gas phase to the liquid film and from the liquid film to the solid phase. For this, the thickness of the diffusion layer is calculated based on the assumption of having a high mass transfer rate in the spinning disc reactor $[20,21]$. Indeed, for flow cell, the mass transfer at the membrane will be much lower, and applying very high current densities $\left(\sim 20 \mathrm{kA} \mathrm{m}^{-2}\right)$ cannot be achieved without reaching the limiting current density. For a proper bilayer model, reliable data for diffusivities of each membrane layer are required. However, in the literature, there are not enough data on diffusivities of all sodium, hydroxide, and chloride ions in the sulfonate and carboxylate layers $[9,10,22]$. The sodium self-diffusion coefficient in both sulfonate and carboxylate membranes has been reported in a sodium chloride and sodium hydroxide solution by Ames [22]. He reported the sodium self-diffusion coefficient to be one order of magnitude higher in the sulfonate layer in both sodium chloride and sodium hydroxide solutions [8,9]. On the other hand, Yeager et al. and Twardowski et al. have measured a slightly higher sodium diffusion coefficient in the sulfonate compared to the carboxylate membranes in sodium chloride solution $[8,22]$. For sake of simplicity, here the selfdiffusivities are assumed to be equal in both layers. The diffusivities are calculated based on the temperature-dependent diffusivity in free water [23]. The calculation of the diffusion coefficients inside the membrane taking into account the effect of tortuosity and porosity, together with the calculation of the total porosity of the membrane has been elaborated in our previous paper [1, 14, 24]. The membrane permselectivity as represented by the sodium transport number is calculated from the ionic fluxes:

$t_{i}=\frac{J_{i} \times F}{I}$

\subsubsection{Modeling conditions and membrane properties}

Table 1 presents the general operating conditions and the membrane characteristics in both mono- and bilayer membranes. Table 2 presents the properties of each membrane layer in the bilayer membrane. The equivalent weights and thickness of each layer are estimated based on the available data for Nafion 954 as an example of a sulfonate/carboxylate bilayer membrane [25].

\subsubsection{Solution strategy}

The convective velocity defined by the Schlögl equation (Eq. 3) is position dependent inside the membrane, and it is calculated with the continuity equation (Eq. 5). At first, an initial guess is required for the total potential gradient over the membrane, and the resulting convective velocity at the 
Table 1 General modeling conditions for both mono- and bilayer membranes
Table 2 Characteristics of sulfonic and carboxylate layers in the bilayer membrane

\begin{tabular}{lll}
\hline Parameter & Value & Reference \\
\hline Temperature $\left({ }^{\circ} \mathrm{C}\right)$ & 80 & \\
Pressure (atm) & 1 & {$[1]$} \\
Sodium hydroxide $(\mathrm{wt} \%)$ & 32 & {$[1]$} \\
Sodium chloride $(\mathrm{wt} \%)$ & 24 & {$[23]$} \\
Sodium diffusivity in free water $\left(\mathrm{m}^{2} \mathrm{~s}^{-1}\right)$ & Correlation & {$[23,26]$} \\
Hydroxide diffusivity in free water $\left(\mathrm{m}^{2} \mathrm{~s}^{-1}\right)$ & Correlation & {$[23]$} \\
Chloride diffusivity in free water $\left(\mathrm{m}^{2} \mathrm{~s}^{-1}\right)$ & Correlation & {$[23]$} \\
Water diffusivity in membrane $\left(\mathrm{m}^{2} \mathrm{~s}^{-1}\right)$ & Correlation & {$[27]$} \\
Mass transfer coefficient in solution $\left(\mathrm{m}^{2} \mathrm{~s}^{-1}\right)$ & $1 \times 10^{-4}$ & {$[27]$} \\
Diffusion layer thickness $(\mathrm{m})$ & $8.3 \times 10^{-6}$ & {$[1]$} \\
Viscosity in the membrane $\left(\mathrm{kg} \mathrm{m}^{-1} \mathrm{~s}^{-1}\right)$ & Correlation \\
Total wet membrane thickness ${ }^{\mathrm{a}}\left(\mathrm{m}^{-1}\right)$ & $2.4 \times 10^{-4}$ & {$[28]$} \\
Dry membrane density $\left(\mathrm{kg} \mathrm{m}{ }^{-3}\right)$ & $2 \times 10^{3}$ & {$[14,29,30]$} \\
Membrane porosity $\left(m_{\mathrm{void}}^{3} / \mathrm{m}_{\mathrm{m}}^{3}\right)$ & 0.27 & {$[24]$} \\
$f_{\mathrm{m}} / f_{\mathrm{e}}$ & 1 & \\
$x_{0}($ midpoint of the logistic curve) & 0 & \\
$k$ (slope of the logistic function) & 120 & \\
\hline
\end{tabular}

${ }^{a}$ Measured with a digital caliper after equilibration in sodium hydroxide solution

\begin{tabular}{llll}
\hline Parameter & Sulfonate & Carboxylate & Reference \\
\hline EW (-) & 1080 & 1050 & {$[25]$} \\
Water content (wt\% dry polymer) & Equation (11) & Equation (12) & {$[1]$} \\
Fixed ionic group concentration $(\mathrm{M})$ & 3.36 & 7.4 & Equation (10) \\
Thickness of layers $(\mathrm{m})$ & $1.54 \times 10^{-4}$ & $0.86 \times 10^{-4}$ & {$[25]$} \\
\hline
\end{tabular}

anolyte side of the membrane is calculated with this total potential gradient by Eq. (3). The local concentration of the species determines the local density inside the membrane. The local convective velocity is calculated with the local density and the equation of continuity (Eq. 5). This is to avoid the violation of the continuity equation. The general material balance (Eq. 8) for the ions is then solved using the pdepe solver in MATLAB. By iterating the model over time, new values of the convective velocity at the anolyte side and the potential gradient are recalculated for each time step. The iteration continues until a steady-state is achieved. The physical scheme of the model is presented in Fig. 2.

\section{Results and discussion}

\subsection{Concentration profiles inside the membrane}

The concentration profiles of the ionic species and water are shown in Fig. 3a-h. Each figure is divided into anolyte and catholyte bulk solutions, boundary layers, and

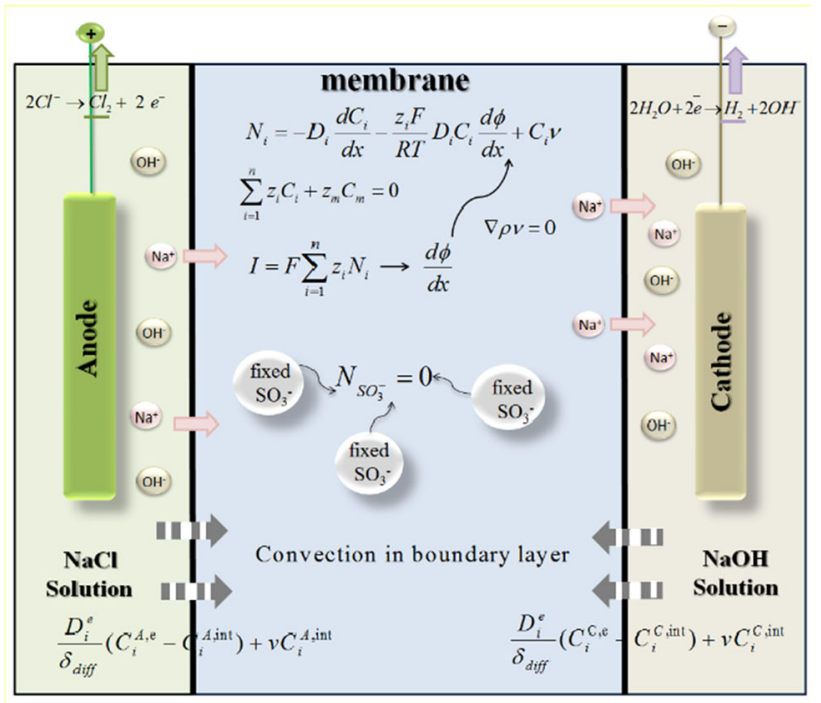

Fig. 2 The physical scheme of the model on a microscopic level with anode and cathode compartments separated by a cation-exchange membrane. The system of equations required to describe the ion transport inside the membrane and at the boundary layers is demonstrated 
membrane layers; regions I and VI present the concentration of the electrolyte solutions in the anode and cathode compartments, respectively. Regions II and V show the concentration profiles in the anolyte and catholyte boundary layers at different current densities. Region III presents the sulfonate layer of the membrane, and region IV presents the carboxylate layer of the membrane. The concentrations of ions and water are assumed constant in the electrolyte bulk solutions. The concentration of the ionic charged species in the boundary layers (regions I and VI) change linearly. The slope slightly increases with increasing current density. This could be explained by the convective flux in the boundary layers. Having a stronger convective flow in the anolyte results in build-up of ion concentration higher than what can be transferred through the membrane. The counter effect occurs at the catholyte side.

As presented in regions III and IV in Fig. 3a, b, the concentration inside the membrane shows an enormous difference between the mono- and bilayer membrane for
Fig. 3 Concentration profile over the solution and the membrane. The position is made dimensionless to only demonstrate different regions: I Anolyte bulk solution. II Anolyte boundary layer thickness. III Sulfonate layer. IV Carboxylate layer. $V$ Catholyte boundary layer thickness. VI

Catholyte bulk solution for a sodium in a monolayer,

b sodium in a bilayer,

c hydroxide in a monolayer, d hydroxide in a bilayer, e chloride in a monolayer, $\mathbf{f}$ chloride in a bilayer, $\mathbf{g}$ water in a monolayer, $\mathbf{h}$ water in a bilayer membrane for a current density range of $0-20 \mathrm{kA} \mathrm{m}^{-2}$. At $T=80^{\circ} \mathrm{C}, 24 \mathrm{wt} \%$ sodium chloride, $32 \mathrm{wt} \%$ sodium hydroxide
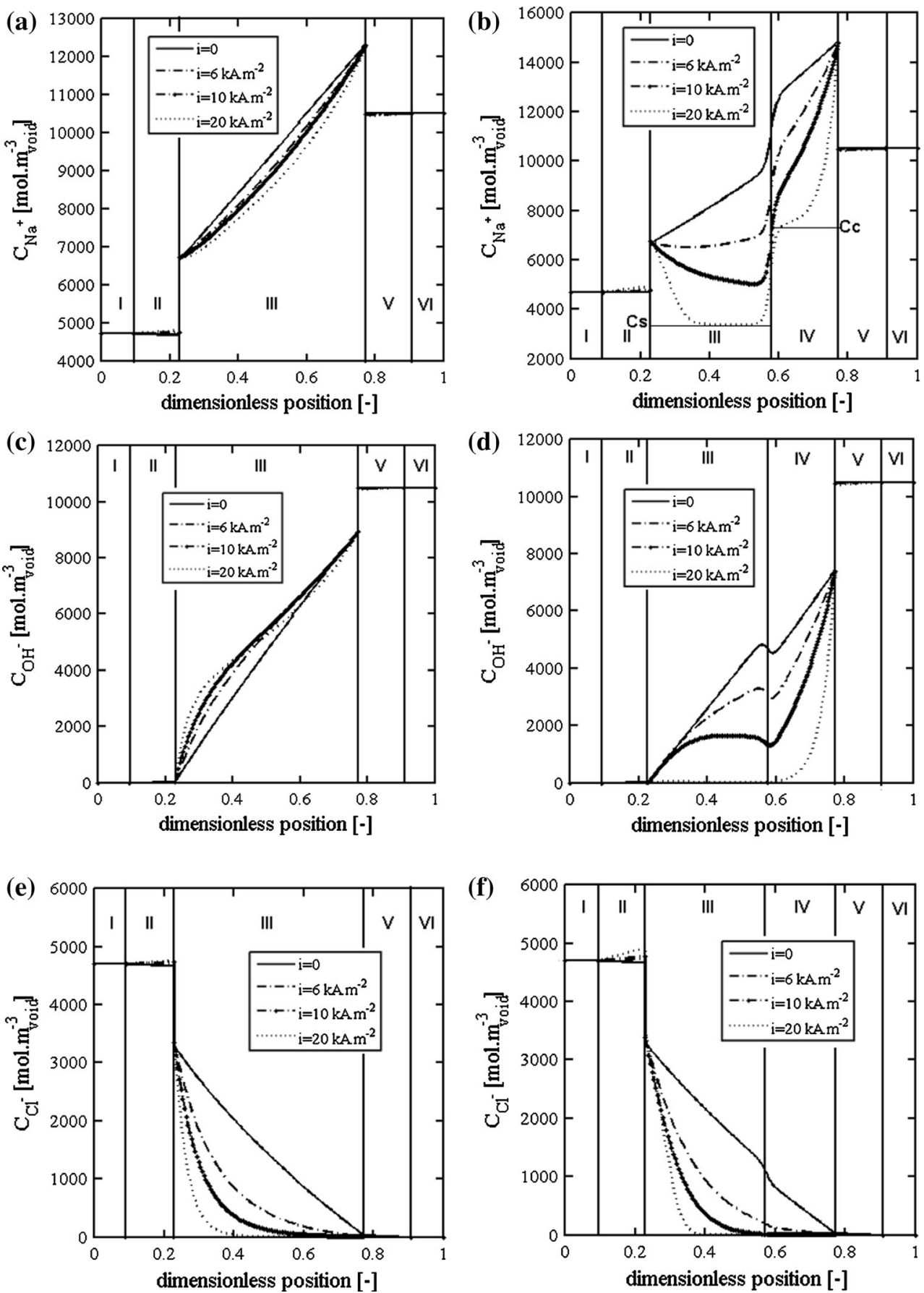
Fig. 3 continued

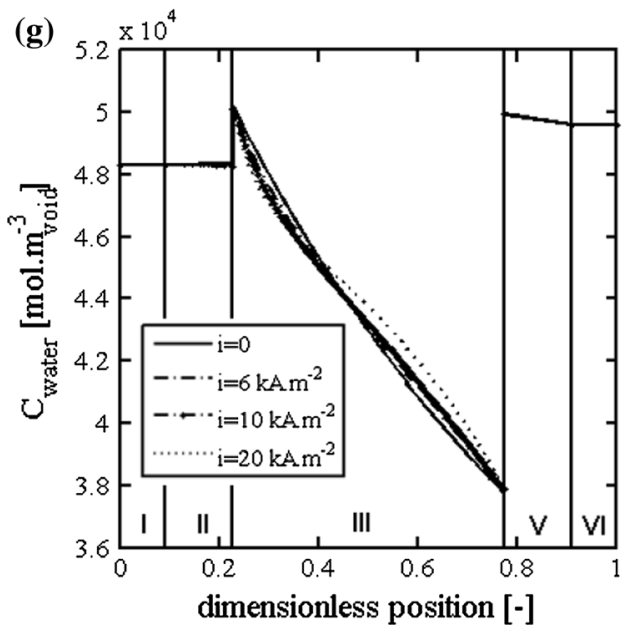

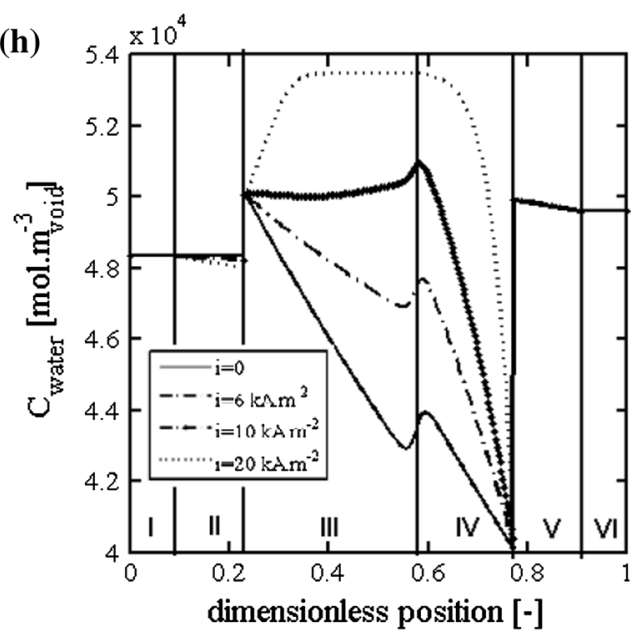

sodium ions. In the monolayer membrane, the concentration increases monotonically between the anolyte and catholyte boundaries. With an increase in current density, the concentration profile becomes more curved. In the bilayer membrane, there is a linear concentration gradient in regions III and IV when no current is applied. As the current density increases, the concentration gradient in region IV becomes steeper, and the sodium ion concentration in region III decreases. At a very high current density $\left(20 \mathrm{kA} \mathrm{m}^{-2}\right)$, a concave plateau is observed in region III which shows that the concentration of sodium ions in this region reaches the limit of the fixed ionic group concentration.

Regions III and IV in Fig. 3c, d present the hydroxide ion concentration inside the mono- and bilayer membranes. In the monolayer membrane, the concentration decreases linearly from the catholyte to the anolyte boundary, and with increasing current density, the concentration profiles become more curved closer to the anolyte boundary. In the bilayer membrane, the concentration gradient is linear in regions III and IV with a steeper change at the interface between the layers. The concentration gradient becomes steeper and more curved in the carboxylate layer with increasing current density, and the concentration profile in region III becomes convex and reaches a plateau value of virtually zero in the membrane with increasing the current density up to $20 \mathrm{kA} \mathrm{m}^{-2}$. The chloride ion concentration inside the membrane is presented in regions III and IV of Fig. 3e, f. It shows a similar trend of concentration change in both mono- and bilayer membranes. As the current density increases a very sharp decrease is observed in chloride ion concentration. The water concentration profile inside the membrane is shown in regions III and IV of Fig. 3g-h. The water concentration is calculated based on the local concentration of the other ions inside the membrane. A decrease in water concentration is observed in the monolayer membrane which is the opposite of the sodium ion concentration. In region IV of the bilayer membrane, a steep decrease in water concentration is observed with increasing the current density; however, a maximum plateau is observed in region III in which the sodium ion concentration is very low and close to the fixed ionic group concentration.

\subsection{Membrane voltage drop and permselectivity}

The membrane voltage drop and permselectivity are the most important parameters for determination of the membrane performance and current efficiency of the process. They have been calculated up to $20 \mathrm{kA} \mathrm{m}^{-2}$ current density. Figure 4 presents the effect of current density on the membrane voltage drop and the sodium selectivity for the mono- and bilayer membranes. Figure $4 \mathrm{a}$ shows that in both the mono- and bilayer membranes, the voltage drop increases when increasing the current density. Additionally, it shows that the membrane voltage drop is higher for the bilayer membrane compared to the monolayer membrane. The sodium transport number is presented in Fig. 4b. In the bilayer membrane, the sodium transport number decreases up to $3 \mathrm{kA} \mathrm{m}^{-2}$ and then increases. There is a general increasing trend of sodium transport number for both mono- and bilayer membranes with increasing the current density, however, it is higher in the bilayer membrane.

\section{Discussion}

The calculated concentration profiles in mono- and bilayer membranes show a large difference in the ion transport between the mono- and bilayer membranes. A lower concentration region in the sulfonate layer is caused because 
Fig. 4 a Membrane voltage drop. b Sodium transport number over a current density range of $2-20 \mathrm{kA} \mathrm{m}^{-2}$ for a mono- and bilayer membrane. At $T=80^{\circ} \mathrm{C}, 24 \mathrm{wt} \%$ sodium chloride and $32 \mathrm{wt} \%$ sodium hydroxide
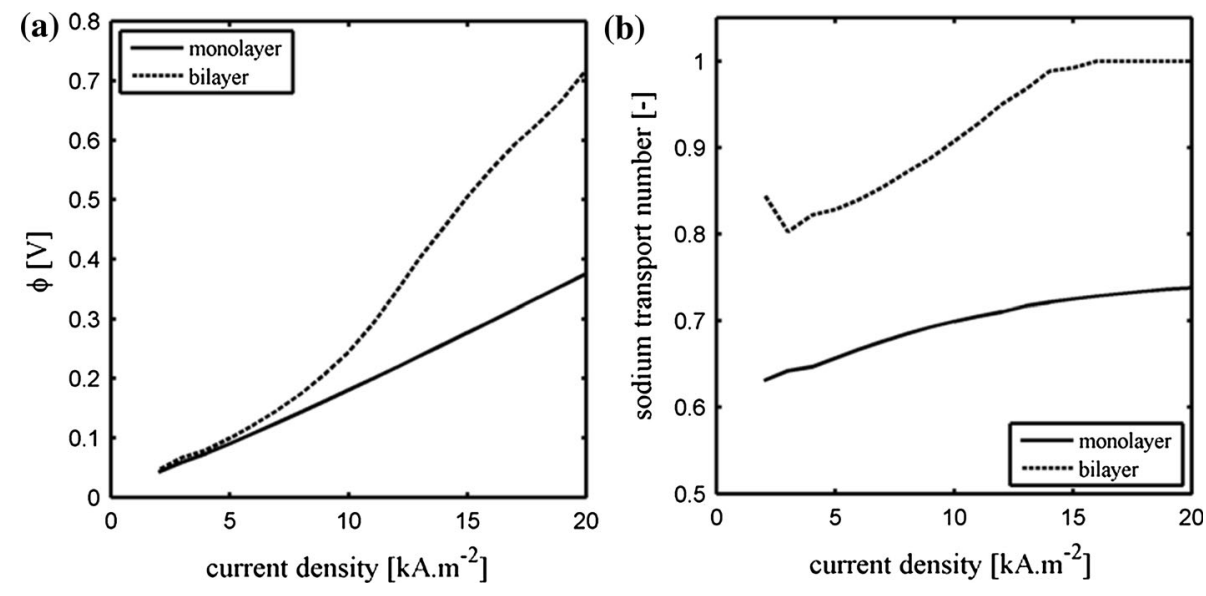

with increasing current density a strong electromotive force in the carboxylate layer dominates the electromotive force in the sulfonate layer. Consequently, the carboxylate layer pulls the ions from the sulfonate layer and reduces the concentration in the sulfonate layer. This way, the diffusive transport in the sulfonate layer increases and compensates for the lower electromotive force. The reduction in sodium concentration between the sulfonate and carboxylate membrane was explained by Takahashi et al. [31]. They used a three compartment cell: a first compartment with anolyte separated with a sulfonate membrane from a second compartment, which is separated with a carboxylate membrane from a third compartment that contains the catholyte. The second compartment was used to represent the interface between a sulfonate and a carboxylate layer in a bilayer membrane. It was shown that the steady-state concentration in the second compartment was significantly lower than the concentration in the first compartment. The current efficiency decreased with decreasing concentration in the second compartment. In our modeling work, we observe that with increasing current density, the sodium concentration in the sulfonate layer decreases to the concentration of fixed ionic groups which is in line with the work presented by Takahashi et al. This suggests that at very high current density, the fixed ionic groups and the sodium counter ions balance each other; and as a consequence, the presence of hydroxide and chloride ions decreases in the sulfonate layer. This results in higher sodium selectivity of the bilayer membrane, and unfortunately also an increase in the membrane resistance. In addition, the sharp decrease of the hydroxide ions in the carboxylate layer confirms that the carboxylate layer at the cathode side prevents the back transport of hydroxide ions in the bilayer membrane especially at high current densities. This results in higher sodium selectivity of the bilayer membrane compared to the monolayer membrane. Furthermore, a steep decrease of the chloride ion concentration at high current densities makes the contribution of transport of chloride ions inside the membrane lower compared to the other ions. The increase of sodium selectivity with increasing current density is not in line with the observed decreasing trend in our earlier paper [14] in a system with identical sodium hydroxide solution as both anolyte and catholyte. However, it is in line with the observed increasing trend of selectivity in the chlor-alkali experiment carried out in the spinning disc membrane electrolyzer explained in our paper elsewhere [32]. The low concentration of water in the carboxylate layer helps the prevention of hydroxide back transport. The high concentration of water in the sulfonate layer with increasing current density should decrease the membrane resistance; however, a decrease of the sodium ion concentration in the sulfonate layer below the anolyte concentration has a higher effect on increasing the overall bilayer membrane resistance.

\section{Conclusion}

Multicomponent ion transport in mono- and bilayer cationexchange membranes has been compared. The concentration profiles of ions inside the membrane show how the extra layer at the catholyte side with a higher electromotive force draws sodium ions from the sulfonate layer. This increases the membrane efficiency in terms of selectivity by decreasing the back transport of hydroxide ions to the anolyte side especially at a high current density of $20 \mathrm{kA} /$ $\mathrm{m}^{2}$, at which the hydroxide concentration in the sulfonate layer is virtually zero. Also, the membrane voltage drop in the bilayer membrane is higher than the monolayer membrane because of the lower sodium concentration. In conclusion, it is shown that the extra carboxylate layer at the cathode side improves the efficiency of the bilayer membranes compared to the monolayer membranes. The slight increase and decrease in concentration of sodium ions at the anolyte and catholyte boundary layers is unexpected. 
This means that the model can be further improved using the Nernst-Planck equation in the solution.

Acknowledgments This project is funded by the Action Plan Process Intensification of the Dutch Ministry of Economic Affairs (Project PI00-04).

Open Access This article is distributed under the terms of the Creative Commons Attribution 4.0 International License (http://crea tivecommons.org/licenses/by/4.0/), which permits unrestricted use, distribution, and reproduction in any medium, provided you give appropriate credit to the original author(s) and the source, provide a link to the Creative Commons license, and indicate if changes were made.

\section{References}

1. O'Brien TF, Bommaraju TV, Hine F (2005) Handbook of chloralkali technology handbook of chlor-alkali technology volume 1: fundamentals. Springer, New York

2. Mauritz KA, Moore RB (2004) State of understanding of Nafion. Chem Rev 104:4535-4585

3. Gebel G (2000) Structural evolution of water swollen perfluorosulfonated ionomers from dry membrane to solution. Polymer 41:5829-5838

4. Schmidt-Rohr K, Chen Q (2008) Parallel cylindrical water nanochannels in nafion fuel-cell membranes. Nat Mater 7:75-83

5. Fujimura M, Hashimoto T, Kawai H (1982) Small-angle X-ray scattering study of perfluorinated ionomer membranes. 2. models for ionic scattering maximum. Am Chem Soc 15:136-144

6. Haubold H, Vad T, Jungbluth H, Hiller P (2001) Nano structure of NAFION: a SAXS study. Electrochim Acta 46:1559-1563

7. Rubatat L, Rollet AL, Diat O (2002) Evidence of elongated polymeric aggregates in nafion. Am Chem Soc 35:4050-4055

8. Twardowski Z, Yeager HL, Dell BO (1982) A comparison of perfluorinated carboxylate and sulfonate ion exchnage polymers: II. Sorption and transport properties in concentrated solution environments. Electrochem Soc 129:328-332

9. Yeager HL, Twardowski Z, Clarke LM (1982) A comparison of perfluorinated carboxylate and sulfonate ion exchange polymers I. Diffusion and water sorption. Electrochem Soc 129:324-327

10. Pintauro PN, Bennlon DN (1984) Mass transport of electrolytes in membranes. 2. Determination of $\mathrm{NaCl}$ equilibrium and transport parameters for nafion. Ind Eng Chem Fundam 23:234-243

11. Rohman FS, Aziz N (2008) Mathematical model of ion transport in electrodialysis process. Chem React Eng Catal 3:3-8

12. Psaltis STP, Farrell TW (2011) Comparing charge transport predictions for a ternary electrolyte using the Maxwell-Stefan and Nernst-Planck equations. J Electrochem Soc 158:A33

13. Graham EE, Dranoff JS (1982) application of the Stefan-Maxwell equations to diffusion in ion exchangers. 1. Theory. Am Chem Soc 21:360-365
14. Moshtarikhah S, Oppers NAW, de Groot MT, et al. (2016) Nernst-Planck modeling of multicomponent ion transport in a Nafion membrane at high current density, in preparation

15. Fíla V, Bouzek K (2008) The effect of convection in the external diffusion layer on the results of a mathematical model of multiple ion transport across an ion-selective membrane. J Appl Electrochem 38:1241-1252

16. Van der Schaaf J, Schouten JC (2011) High-gravity and highshear gas-liquid contactors for the chemical process industry. Curr Opin Chem Eng 1:84-88

17. Jachuck RJ, Ramshaw C, Boodhoo K, Dalgleish JC (1997) Process intensification: the opportunity presented by spinning disc reactor technology. In: ICHEME, pp 417-424

18. Ramshaw C (1993) The opportunities for exploiting centrifugal fields. Heat Recover Syst CHP 13:493-513

19. Meeuwse M (2011) Rotor-stator spinning disc reactor. Eindhoven University of Technology, Eindhoven

20. Van der Schaaf J, Schouten JC (2011) High-gravity and highshear gas-liquid contactors for the chemical process industry. Curr Opin Chem Eng 1:84-88

21. Meeuwse M (2011) Rotor-stator spinning disc reactor. Technische Universiteit Eindhoven, Eindhoven

22. Ames RL (2004) Nitric acid dehydration using perfluoro carboxylate and mixed sulfonate/carboxylate membranes. University of California, berkeley

23. Baştuğ T, Kuyucak S (2005) Temperature dependence of the transport coefficients of ions from molecular dynamics simulations. Chem Phys Lett 408:84-88

24. Yeo RS (1983) Ion clustering and proton transport in nafion membranes and its applications as solid polymer electrolyte. J Electrochem Soc 130:533-538

25. Grot W (2011) Fluorinated ionomers. William Andrew, Oxford

26. Samson E, Marchand J, Snyder KA (2003) Calculation of ionic diffusion coefficients on the basis of migration test results. Mater Struct 36:156-165

27. Granados Mendoza P (2016) Liquid solid mass transfer to a rotating mesh electrode. Heat Mass Transf 104:650-657

28. Grot W (2011) Fluorinated Ionomers, PDL Handbook series. William Andrew, p 58

29. Tiss F, Chouikh R, Guizani A (2013) A numerical investigation of the effects of membrane swelling in polymer electrolyte fuel cells. Energy Convers Manag 67:318-324

30. Chi PH, Chan SH, Weng FB et al (2010) On the effects of nonuniform property distribution due to compression in the gas diffusion layer of a PEMFC. Int J Hydrogen Energy 35:2936-2948

31. Takahashi Y, Obanawa H, Noaki Y (2001) New electrolyser design for high current density. Mod Chlor Alkali Technol 8:8

32. Granados Mendoza P, Moshtarikhah S, de Groot MT, et al. (2016) Intensification of the chlor-alkali process by using a spinning disc membrane electrolyzer, in preparation 